\title{
Nosocomial infections among patients with COVID-19, SARS and MERS: a rapid review and meta-analysis
}

\author{
Qi Zhou ${ }^{1,2 \#}$, Yelei Gao ${ }^{3,4,5 \#}$, Xingmei Wang ${ }^{3,4,5 \#}$, Rui Liu ${ }^{3,4,5}$, Peipei Du ${ }^{6}$, Xiaoqing Wang ${ }^{3,4,5}$, \\ Xianzhuo Zhang ${ }^{1,2}$, Shuya $\mathrm{Lu}^{2,7,8}$, Zijun Wang ${ }^{2}$, Qianling Shi ${ }^{1,2}$, Weiguo $\mathrm{Li}^{3,4,5}$, Yanfang $\mathrm{Ma}^{2}$, Xufei Luo ${ }^{9}$, Toshio \\ Fukuoka $^{10,11}$, Hyeong Sik Ahn ${ }^{12,13}$, Myeong Soo Lee ${ }^{14,15}$, Enmei Liu ${ }^{3,45}$, Yaolong Chen ${ }^{2,16,17,18}$, Zhengxiu Luo ${ }^{3,4,5}$, \\ Kehu Yang ${ }^{1,2,18}$; on behalf of COVID-19 Evidence and Recommendations Working Group
}

${ }^{1}$ The First School of Clinical Medicine, Lanzhou University, Lanzhou 730000, China; ${ }^{2}$ Evidence-based Medicine Center, School of Basic Medical Sciences, Lanzhou University, Lanzhou 730000, China; ${ }^{3}$ Department of Respiratory Medicine, Children's Hospital of Chongqing Medical University, Chongqing 400014, China; ${ }^{4}$ National Clinical Research Center for Child Health and Disorders, Ministry of Education Key Laboratory of Child Development and Disorders, China International Science and Technology Cooperation Base of Child Development and Critical Disorders, Children's Hospital of Chongqing Medical University, Chongqing 400014, China; 'Chongqing Key Laboratory of Pediatrics, Chongqing 400014, China; ${ }^{6}$ School of Public Health, Chengdu Medical College, Chengdu 610500, China; ${ }^{7}$ Department of Pediatric, Sichuan Provincial People's Hospital, University of Electronic Science and Technology of China, Chengdu 611731, China; ${ }^{8}$ Chinese Academy of Sciences Sichuan Translational Medicine Research Hospital, Chengdu 610072, China; ${ }^{9}$ School of Public Health, Lanzhou University, Lanzhou 730000, China; ${ }^{10}$ Emergency and Critical Care Center, the Department of General Medicine, Department of Research and Medical Education at Kurashiki Central Hospital, Kurashiki, Japan; ${ }^{11}$ Advisory Committee in Cochrane Japan, Tokyo, Japan; ${ }^{12}$ Department of Preventive Medicine, Korea University College of Medicine, Seoul, Korea; ${ }^{13}$ Korea Cochrane Centre, Seoul, Korea; ${ }^{14}$ Korea Institute of Oriental Medicine, Daejeon, Korea; ${ }^{15}$ University of Science and Technology, Daejeon, Korea; ${ }^{16}$ Lanzhou University, an Affiliate of the Cochrane China Network, Lanzhou 730000, China; ${ }^{17}$ Chinese GRADE Center, Lanzhou 730000, China; ${ }^{18}$ Key Laboratory of Evidence Based Medicine and Knowledge Translation of Gansu Province, Lanzhou University, Lanzhou 730000, China

Contributions: (I) Conception and design: Y Chen, E Liu; (II) Administrative support: Y Chen; (III) Provision of study materials or patients: Y Gao, R Liu, X Wang; (IV) Collection and assembly of data: R Liu, X Wang, Y Gao, P Du, X Wang, X Zhang, S Lu, Z Wang; (V) Data analysis and interpretation: Q Zhou, Q Shi, Y Gao; (VI) Manuscript writing: All authors; (VII) Final approval of manuscript: All authors.

"These authors contributed equally to this work.

Correspondence to: Kehu Yang. The First School of Clinical Medicine, Evidence-based Medicine Center, School of Basic Medical Sciences, Lanzhou University, Lanzhou 730000, China. Email: kehuyangebm2006@126.com; Zhengxiu Luo. Department of Respiratory Medicine, Children’s Hospital of Chongqing Medical University, Chongqing 400014, China. Email: luozhengxiu816@163.com.

Background: COVID-19, a disease caused by SARS-CoV-2 coronavirus, has now spread to most countries and regions of the world. As patients potentially infected by SARS-CoV-2 need to visit hospitals, the incidence of nosocomial infection can be expected to be high. Therefore, a comprehensive and objective understanding of nosocomial infection is needed to guide the prevention and control of the epidemic.

Methods: We searched major international and Chinese databases: Medicine, Web of Science, Embase, Cochrane, CBM (China Biology Medicine disc), CNKI (China National Knowledge Infrastructure) and Wanfang database for case series or case reports on nosocomial infections of COVID-19, SARS (severe acute respiratory syndromes) and MERS (Middle East respiratory syndrome) from their inception to March 31st, 2020. We conducted a meta-analysis of the proportion of nosocomial infection patients in the diagnosed patients, occupational distribution of nosocomial infection medical staff.

Results: We included 40 studies. Among the confirmed patients, the proportions of nosocomial infections with early outbreaks of COVID-19, SARS, and MERS were $44.0 \%, 36.0 \%$, and $56.0 \%$, respectively. Of the confirmed patients, the medical staff and other hospital-acquired infections accounted for $33.0 \%$ and $2.0 \%$ of COVID-19 cases, $37.0 \%$ and $24.0 \%$ of SARS cases, and $19.0 \%$ and $36.0 \%$ of MERS cases, respectively. Nurses and doctors were the most affected among the infected medical staff. The mean numbers of secondary cases caused by one index patient were 29.3 and 6.3 for SARS and MERS, respectively. 
Conclusions: The proportion of nosocomial infection in patients with COVID-19 was 44\% in the early outbreak. Patients attending hospitals should take personal protection. Medical staff should be awareness of the disease to protect themselves and the patients.

Keywords: COVID-19; meta-analysis; nosocomial infection; rapid review

Submitted Apr 15, 2020. Accepted for publication Apr 30, 2020.

doi: 10.21037/atm-20-3324

View this article at: http://dx.doi.org/10.21037/atm-20-3324

\section{Introduction}

COVID-19 is a respiratory infectious disease caused by a novel coronavirus, SARS-CoV-2. The first batch of COVID-19 patients were found in December 2019 (1). The disease is mainly transmitted through respiratory droplets and close contact, and all people are susceptible to it (2). SARS-CoV-2 is highly contagious (3), and has quickly spread to most countries and regions of the world. COVID-19 has become a global pandemic and has received great attention from all over the world $(4,5)$. As of April 7, 2020, 1,214,466 confirmed cases of COVID-19 have been found in 211 countries and regions, causing 67,767 deaths (6).

The main clinical manifestations of COVID-19 are cough, fever and complications such as acute respiratory distress syndrome (1). Disease clusters and nosocomial infections have been reported $(7,8)$. The proportion of nosocomial infections is high among diagnosed infections, and medical staff are at high risk of infection (8). One study on 44,672 patients showed that health workers accounted for $3.8 \%$ of the COVID-19 cases and five health workers died as a result of the infection (9). There is still no specific medicine for COVID-19, so preventing nosocomial infections is crucial.

This study compares the incidence of nosocomial infections during the COVID-19, SARS and MERS epidemics and analyzes the characteristics of the nosocomial infection, to enhance the understanding of nosocomial infection among medical and non-medical staff. We present the following article in accordance with the PRISMA reporting checklist (available at http://dx.doi.org/10.21037/ atm-20-3324).

\section{Methods}

\section{Search strategy}

An experienced librarian searched the following databases from their inception to March 31, 2020 in the following electronic databases (10): the Cochrane Library, MEDLINE (via PubMed), EMBASE, Web of Science, CBM (China Biology Medicine disc), CNKI (China National Knowledge Infrastructure), and Wanfang database. We made no restrictions on language or publication status. We used the following search formula is as follow: ("Novel coronavirus" OR "2019-novel coronavirus" OR "Novel CoV" OR "2019-nCoV" OR "COVID-19" OR "SARS-CoV-2" OR "Middle East Respiratory Syndrome" OR "MERS" OR "MERS-CoV" OR "Severe Acute Respiratory Syndrome" OR "SARS" OR "SARS-CoV" OR "SARS-Related" OR "SARS-Associated") AND ("Cross Infection" OR "Cross Infections" OR "Healthcare Associated Infections" OR "Healthcare Associated Infection" OR "Health Care Associated Infection "OR "Health Care Associated Infections" OR "Hospital Infection" OR "Nosocomial Infection" OR "Nosocomial Infections" OR "Hospital Infections" OR "hospital-related infection" OR "hospitalacquired infection"). We also searched clinical trial registry platforms [the World Health Organization Clinical Trials Registry Platform (http://www.who.int/ictrp/en/), US National Institutes of Health Trials Register (https:// clinicaltrials.gov/)], Google Scholar (https://scholar.google. $\mathrm{nl} /$ ), preprint platform [medRxiv (https://www.medrxiv. org/), bioRxiv (https://www.biorxiv.org/) and SSRN (https:// www.ssrn.com/index.cfm/en/)] and reference lists of the included reviews to find unpublished or further potential studies. Finally, we contacted experts in the field to identify relevant trials. The search strategy was also reviewed by another information specialist. The details of the search strategy can be found in the Supplement I.

\section{Inclusion and exclusion criteria}

We included case series studies and case reports about the proportion of cases of COVID-19, SARS and MERS who were infected in health facilities, about infections among 
medical staff and outbreaks in hospitals. Abstract, letter, new, guideline, articles for which we could not access all relevant data or full text were excluded.

\section{Study selection}

After eliminating duplicates, two reviewers (Y Gao and $\mathrm{X}$ Wang) independently selected the relevant studies in two steps with the help of the EndNote software. Discrepancies were settled by discussion or consulting a third reviewer (Q Zhou). In the first step, all titles and abstracts were screened using pre-defined criteria. In the second step, full-texts of the potentially eligible and unclear studies were reviewed to decide about final inclusion. All reasons for exclusion of ineligible studies were recorded. The process of study selection was documented using a PRISMA flow diagram (11).

\section{Data extraction}

Two reviewers (R Liu and X Wang) extracted the data independently using a standardized data collection table. Any differences were resolved by consensus, and a third auditor checked the consistency and accuracy of the data. The following data were extracted: (I) basic information: title, first author, country, year of publication, and type of study; (II) population baseline characteristics: age and sex distribution, and sample size; and (III) the proportion of nosocomial infections, the proportion of patients with occupation of medical staff, and for studies on hospital outbreaks, the number of index cases and total infections.

\section{Risk of bias assessment}

Two researchers ( $Z$ Wang and Q Shi) independently assessed the potential bias in each included study. The included studies were evaluated using appropriate assessment scales depending on the study type: for case control studies, the Newcastle-Ottawa Scale (NOS) (12), for cross-sectional studies and epidemiological surveys, the methodology evaluation tool recommended by the Agency for Healthcare Research and Quality (AHRQ) (13), and for case reports and case series, we used a methodology evaluation tool recommended by National Institute for Health and Care Excellence (NICE) (14).

\section{Data synthesis}

We performed a meta-analysis of proportions for dichotomous outcomes (nosocomial infection among the confirmed cases, and infections among the health care workers), reporting the effect size (ES) with $95 \%$ confidence intervals (CI) by using random-effects models. Two-sided $P$ values $<0.05$ were considered statistically significant. Heterogeneity was defined as $\mathrm{P}<0.10$ and $\mathrm{I}^{2}>50 \%$. All analyses were performed in STATA version 14. All results are limited to $0-100 \%$.

\section{Quality of the evidence assessment}

Two reviewers ( $Z$ Wang and Q Shi) assessed the quality of evidence independently using the Grading of Recommendations Assessment, Development and Evaluation (GRADE) $(15,16)$. We produced a "Summary of Findings" table using the GRADEpro software. This table includes overall grading of evidence body for each prespecified outcome that is accounted in a metaanalysis. The overall quality can be downgraded for five considerations (study limitations, consistency of effect, imprecision, indirectness, and publication bias) and upgraded for three considerations (large magnitude of effect, dose-response relation and plausible confounders or biases). The overall quality of evidence will be classified as high, moderate, low or very low, which reflecting to what extent that we can be confident the effect estimates are correct.

As COVID-19 is a public health emergency of international concern and the situation is evolving rapidly, our study was not registered in order to speed up the process (17).

\section{Results}

\section{Characteristics and quality of included studies}

Our initial search revealed 2,626 articles, of which 2,598 were left after deleting the duplicates (Figure 1). After review the titles and abstracts, we screened the full texts of 66 articles, of which 40 were finally included (Table 1). Four studies were about COVID-19 (8,18-20), 25 studies about SARS (21-45), and 11 studies about MERS (46-56) (Table 1). Sixteen 


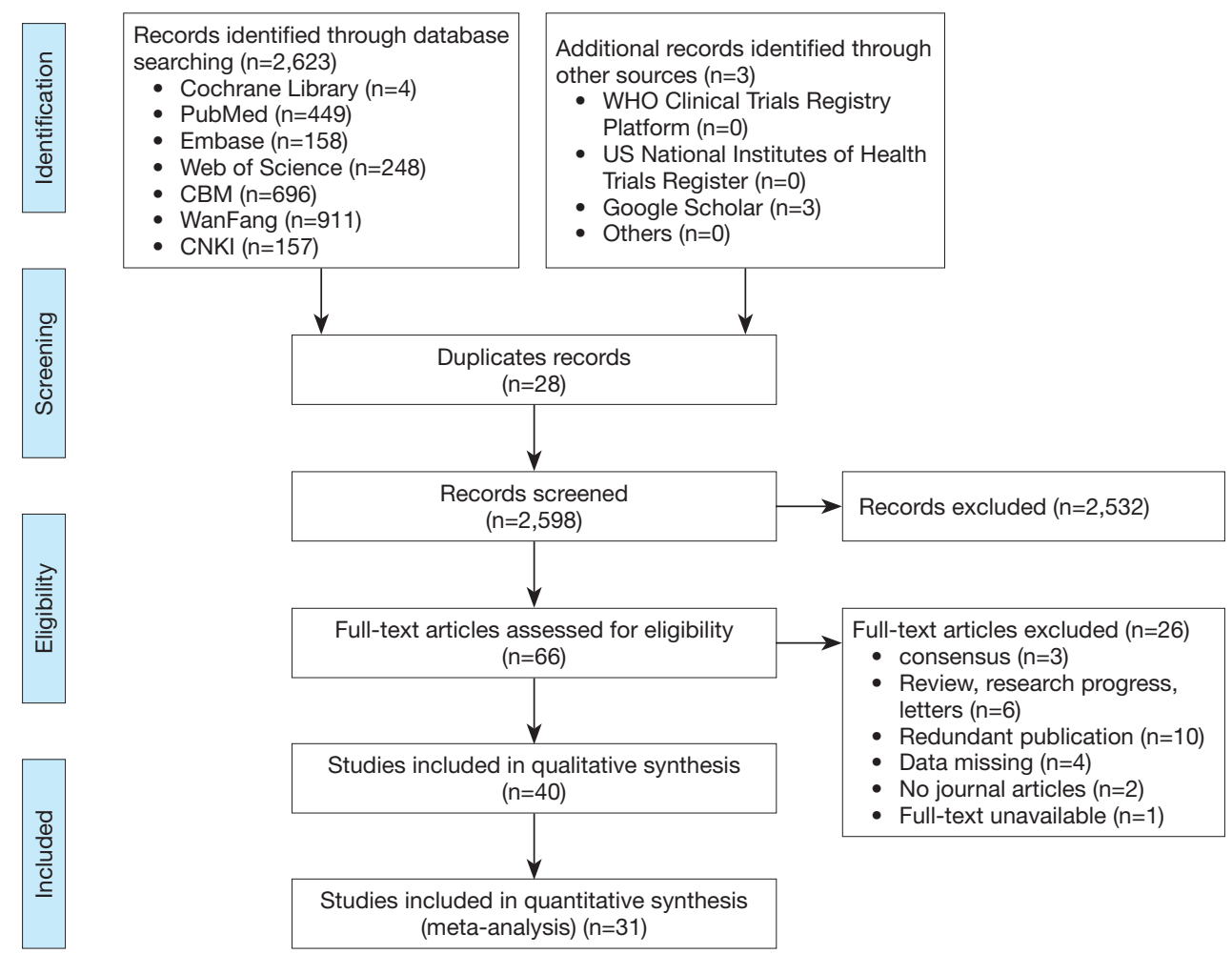

Figure 1 Flow diagram of the literature search.

studies described the number of nosocomial infections in a selected patient population, 16 studies described the situation of nosocomial infections among the staff of medical institutions, and 13 studies reported the number of nosocomial infections caused by one or more than one patient. The quality of included studies was very poor: all cross-sectional studies scored less than 8 out of 11 in the evaluation by the AHRQ tool, half case series studies scored less than 5 out of 8 in the evaluation by the NICE tool, and only one case-control study scored 6 by the NOS tool. The details of the risk of bias of included studies can be found in the Supplement II (Tables S1-S3).

\section{Nosocomial infections among confirm cases}

The proportion of nosocomial infections was $44.0 \%$ (95\% CI: 0.36 to $0.51 ; \mathrm{I}^{2}=0.00 \%$ ) among COVID-19 patients in the early outbreak, $36.0 \%$ (95\% CI: 0.23 to $0.49 ; \mathrm{I}^{2}=97.8 \%$ ) among SARS patients, and 56.0\% (95\% CI: 0.08 to 1.00; $\mathrm{I}^{2}=99.9 \%$ ) among MERS patients (Figure 2). Thirty-three percent (95\% CI: 0.27 to $0.40 ; I^{2}=0.00 \%$ ) of patients with
COVID-19 were medical staff, and 2.0\% (95\% CI: 0.01 to $0.03 ; \mathrm{I}^{2}=0.00 \%$ ), were nosocomial infections among people other than medical staff (such as inpatients or visitors). The corresponding proportions among SARS patients were $37.0 \%$ (95\% CI: 0.25 to $0.49 ; \mathrm{I}^{2}=97.3 \%$ ) and $24.0 \%$ (95\% CI: 0.10 to $0.38 ; \mathrm{I}^{2}=86.6 \%$ ), and $19.0 \%$ (95\% CI: 0.04 to $0.35 ; \mathrm{I}^{2}=97.8 \%$ ) and $36.0 \%$ (95\% CI: 0.06 to 0.67 ; $\mathrm{I}^{2}=99.3 \%$ ) among MERS patients (Figures 3,4).

\section{Infection among the health care workers}

Twenty studies mentioned infection among the health workers, of which sixteen studies described the occupational composition of infected health care workers. Doctors accounted for $33.0 \%$ (95\% CI: 0.24 to 0.44 ), nurses $56.0 \%$ ( $95 \%$ CI: 0.45 to 0.66 ), and other staff (such as carers, cleaners, hospital support staff) $11.0 \%$ (95\% CI: 0.06 to 0.20) of COVID-19 cases among hospital staff in the early outbreak in Wuhan. For SARS, 30.0\% (95\% CI: 0.19 to $\left.0.40 ; \mathrm{I}^{2}=91.1 \%\right)$ of the cases among hospital workers were doctors, $50.0 \%$ (95\% CI: 0.45 to $0.55 ; \mathrm{I}^{2}=38.8 \%$ ) nurses, 
Table 1 Characteristics of included studies

\begin{tabular}{|c|c|c|c|c|c|}
\hline Study ID & Disease & Study type & Time & Location of the study & Sample size \\
\hline Wang 2020 (18) & COVID-19 & Case series & 2020.01.01-2020.01.28 & Hubei & 451 \\
\hline Jiang 2020 (19) & COVID-19 & Case series & 2019.12.15-2020.02.15 & Wuhan & 41 \\
\hline Shen 2020 (20) & COVID-19 & Case control study & 2020.01.15-2020.02.08 & Wuhan & 158 \\
\hline Dai 2004 (22) & SARS & Cross-sectional study & 203.01.18-2003.03.08 & Guangdong & 230 \\
\hline Zou 2004 (23) & SARS & Cross-sectional study & To 2003.05 & Guangdong & 2,635 \\
\hline Wang 2003 (24) & SARS & Cross-sectional study & 2003.01.02-2003.04.17 & Guangdong & 966 \\
\hline Gao 2003 (25) & SARS & Cross-sectional study & 2003.05.14-2003.05.17 & Guangdong & 86 \\
\hline Gao 2003 (28) & SARS & Cross-sectional study & To 2003.07.07 & - & 669 \\
\hline Yuan 2003 (29) & SARS & Cross-sectional study & 2003.01-2003.06.20 & Shenzhen & 53 \\
\hline Wang 2003 (30) & SARS & Cross-sectional study & 2003.04.13-2003.05.08 & Tianjin & 175 \\
\hline Wang 2003 (31) & SARS & Cross-sectional study & 2003.04.20-2003.05.18 & Tianjin & 2,300 \\
\hline Wu 2004 (32) & SARS & Cross-sectional study & 2003.03.27-2003.06.24 & Beijing & 1,861 \\
\hline Huang 2003 (33) & SARS & Cross-sectional study & 2003.02.02-2002.05 & Guangdong & 454 \\
\hline Li 2003 (34) & SARS & Cross-sectional study & 2002.12.26-2003.01.19 & Zhongshan & 29 \\
\hline Fei 2003 (35) & SARS & Cross-sectional study & 2003.03-2003.04 & Beijing & 33 \\
\hline Fowler 2003 (40) & & & & & 164 \\
\hline Varia 2003 (41) & SARS & Cross-sectional study & - & Toronto & 128 \\
\hline Lau 2004 (42) & SARS & Cross-sectional study & - & Hong Kong & 339 \\
\hline Zhou 2004 (43) & SARS & Cross-sectional study & 2003.01.05-2003.05.09 & Guangdong & 1,645 \\
\hline Chen 2006 (44) & SARS & Cross-sectional study & To 2003.07 & Singapore & 105 \\
\hline \multirow[t]{3}{*}{ Cooper 2009 (45) } & SARS & Cross-sectional study & 2003.02.21-2003.03.28 & Beijng & 41 \\
\hline & & Cross-sectional study & 2003.03.25-2003.04.12 & Beijng & 99 \\
\hline & & Cross-sectional study & 2003.04.16-2003.05.12 & Tianjin & 91 \\
\hline Oboho 2015 (46) & MERS & Cross-sectional study & 2014.01.01-2014.05.01 & Saudi Arabia & 255 \\
\hline Xiang 2015 (47) & MERS & Cross-sectional study & 2015.5.20-2015.7.13 & South Korea & 186 \\
\hline Assiri 2013 (48) & MERS & Case series & 2013.04.01-2013.07.12 & Saudi Arabia & 447 \\
\hline
\end{tabular}

Table 1 (Continued) 
Table 1 (Continued)

\begin{tabular}{|c|c|c|c|c|c|}
\hline Study ID & Disease & Study type & Time & Location of the study & Sample size \\
\hline Memish 2015 (50) & MERS & Cross-sectional study & 2013.08.24-2013.09.03 & Saudi Arabia & 306 \\
\hline \multirow[t]{2}{*}{ Park 2016 (51) } & MERS & Cross-sectional study & 2015.05.20-2015.07.19 & South Korea & 76 \\
\hline & & & & & 70 \\
\hline Hunter 2016 (53) & MERS & Cross-sectional study & 2013.01.01-2014.05.09 & Saudi Arabia & 65 \\
\hline Amer 2018 (54) & MERS & Cross-sectional study & 2017.03.31-2017.07.15 & Saudi Arabia & 120 \\
\hline Cho 2016 (55) & MERS & Case series & 2015.05.27-2015.05.29 & South Korea & 1,576 \\
\hline Hijawi 2013 (56) & MERS & Cross-sectional study & 2012.04.01-2012.09.30 & Jordan & 13 \\
\hline
\end{tabular}

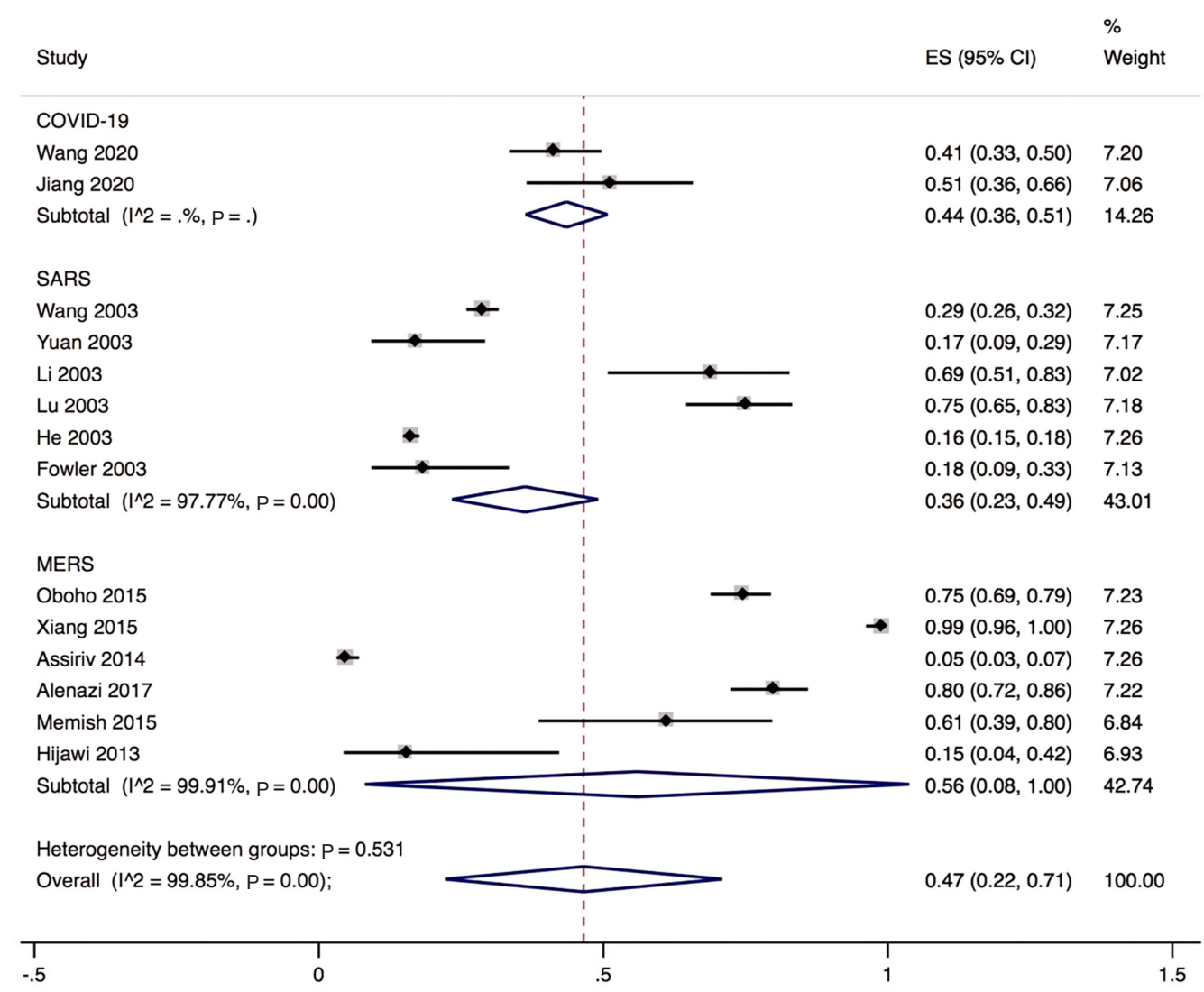

Figure 2 The proportion of nosocomial infections among confirm cases of COVID-19, SARS and MERS.

and $21.0 \%\left(95 \% \mathrm{CI}: 0.12\right.$ to $\left.0.29 ; \mathrm{I}^{2}=85.2 \%\right)$ others. For MERS, for the corresponding proportions were $35.0 \%$ (95\% CI: 0.14 to $\left.0.56 ; \mathrm{I}^{2}=0.00 \%\right), 50.0 \%(95 \%$ CI: 0.29 to $\left.0.71 ; \mathrm{I}^{2}=0.00 \%\right)$ and $16.0 \%$ (95\% CI: 0.00 to $\left.0.32 ; \mathrm{I}^{2}=0.00 \%\right)$. For all three conditions combined, the proportion of doctors among infected hospital staff was $30.0 \%, 51.0 \%$ for the proportion of nurses, and $19.0 \%$ for the proportion of others (Figures 5-7). 


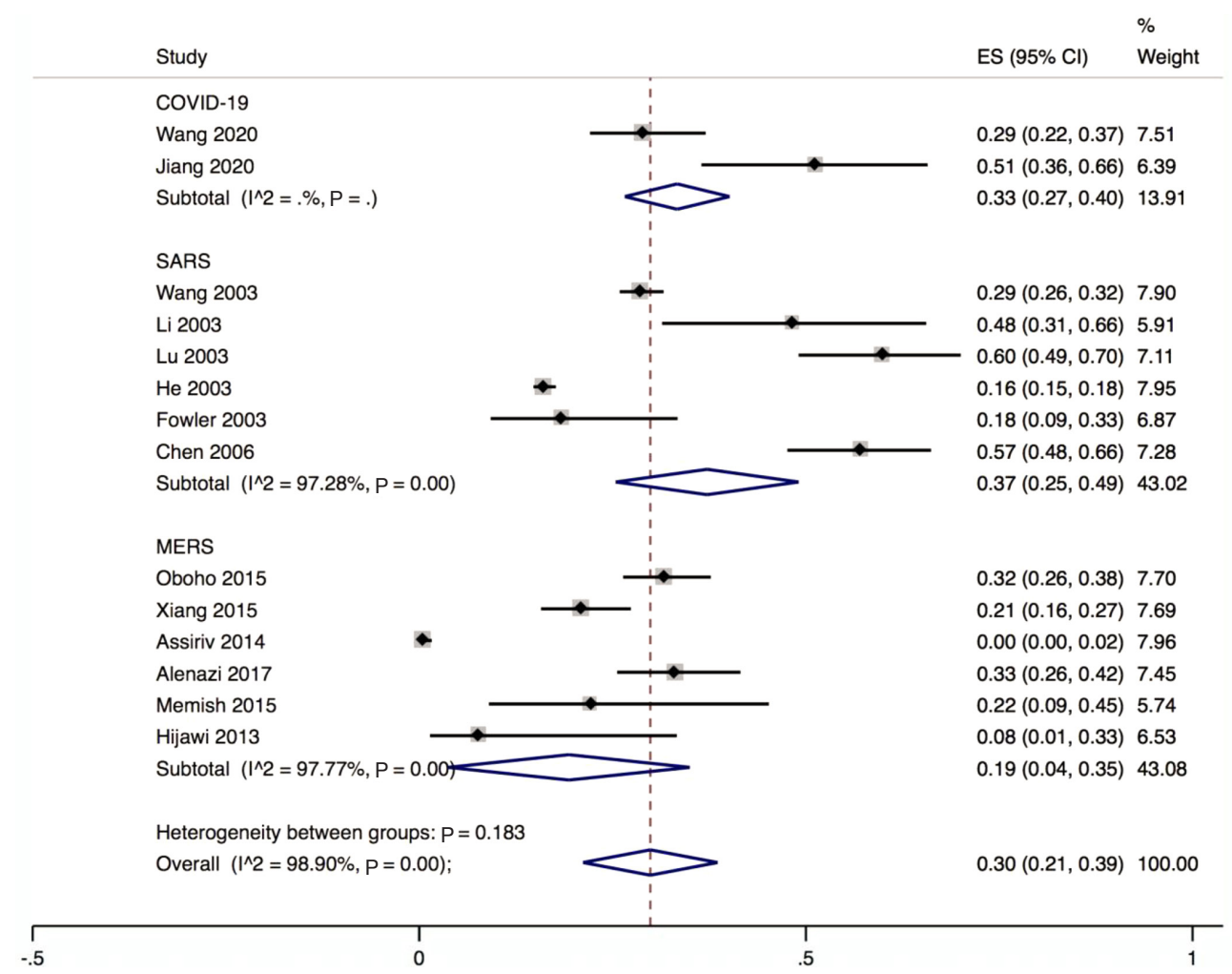

Figure 3 Proportions of health care workers among confirmed cases of COVID-19, SARS and MERS.

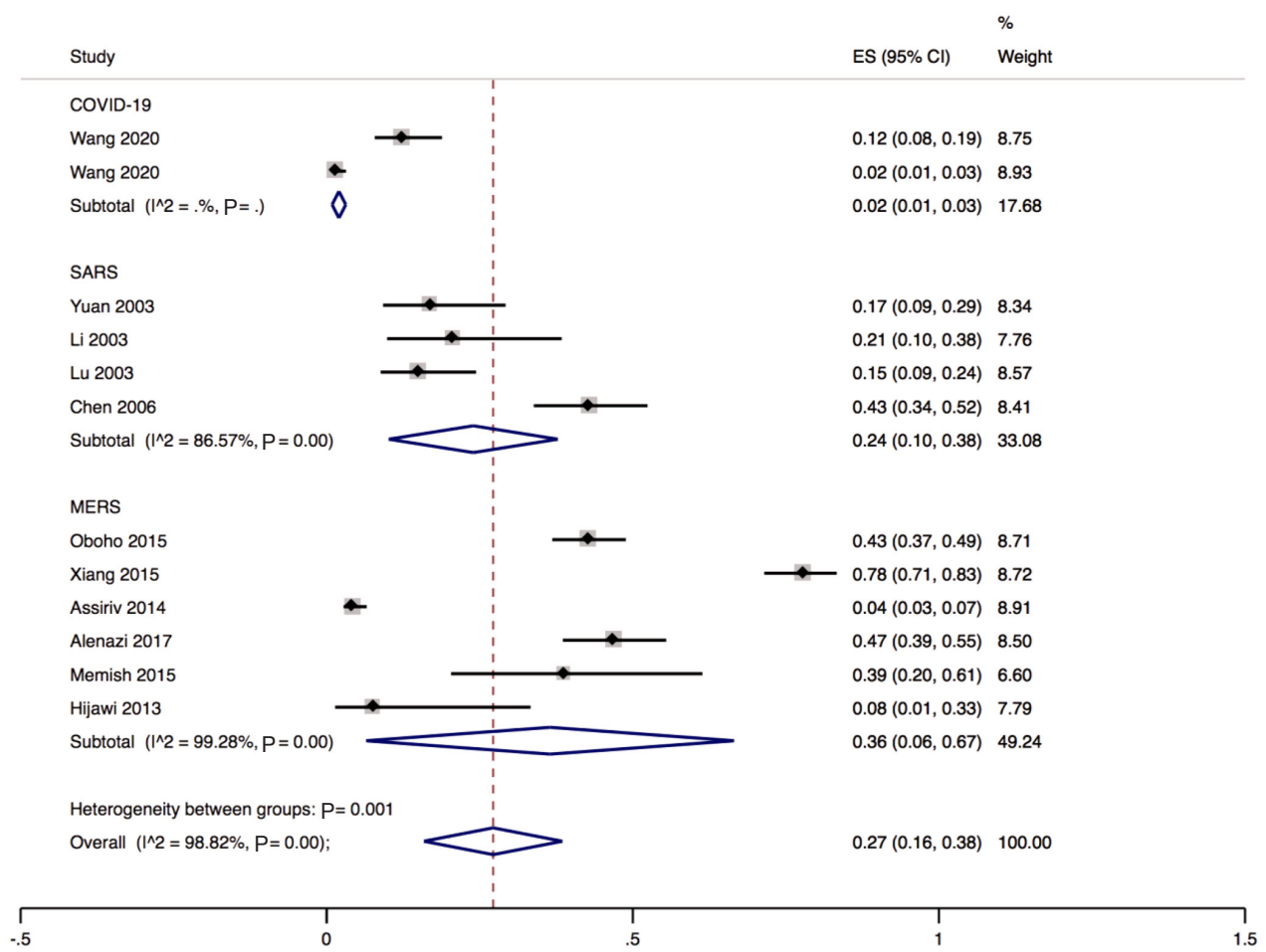

Figure 4 Proportions of nosocomial infections excluding health care workers among confirm cases of COVID-19, SARS and MERS. 


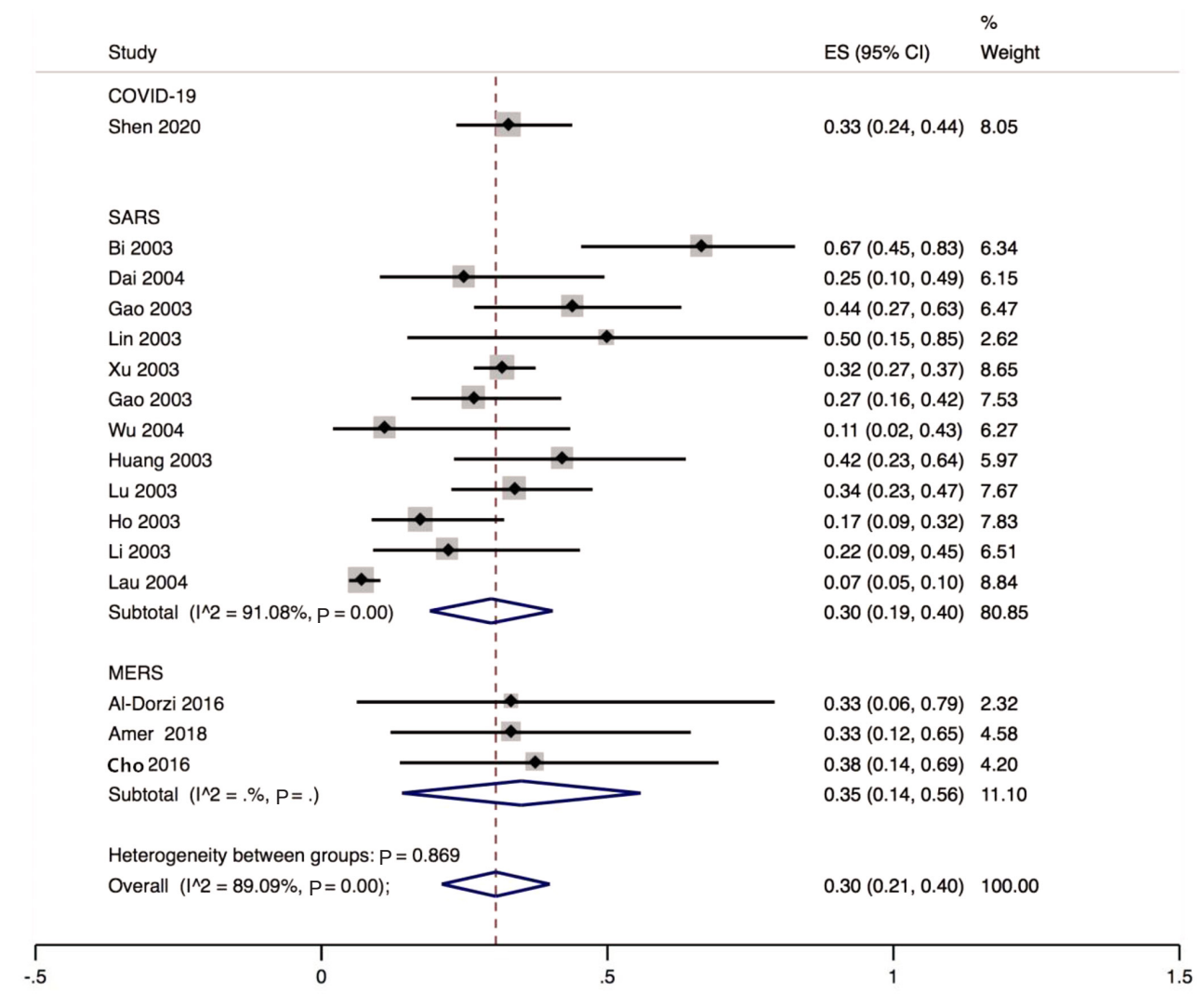

Figure 5 Proportion of doctors among hospital staff with COVID-19, SARS and MERS.

Five studies described the protective measures of medical staff infected with SARS in hospital. Sixty-three percent (95\% CI: 0.35 to $0.92 ; \mathrm{I}^{2}=96.1 \%$ ) of the infected staff did not wear protective clothing ), $58.0 \%$ (95\% CI: 0.39 to $\left.0.76 ; \mathrm{I}^{2}=0.00 \%\right)$ did not use gloves , $91.0 \%$ (95\% CI: 0.80 to $\left.1.00 ; \mathrm{I}^{2}=0.00 \%\right)$ did not wear goggles; $57.0 \%$ (95\% CI: 0.00 to $1.00 ; \mathrm{I}^{2}=0.00 \%$ ) did not take any hand disinfection measures), and $7.0 \%$ (95\% CI: 0.00 to $0.16 ; \mathrm{I}^{2}=0.00 \%$ ) did not wear masks (Figure 8). One study described that among the 22 infected medical workers, 21 had no shoe cover. One study described that of 53 infected health workers, 47 wore cloth masks.

\section{Outbreaks in the hospitals}

Six studies described SARS outbreaks, and five studies MERS outbreaks that happened in hospitals. The SARS studies reported on 23 patients, causing a total of 674 infections in hospitals, with an average of 29.3 infections per index patient. The MERS studies reported 24 patients causing 152 infections in hospitals, with an average of 6.3 infections per index patient (Table 2).

\section{Quality of evidence}

The results of GRADE on nosocomial infections showed that the quality of evidence were low or very low. The details can be found in the Supplement III (Table S4).

\section{Discussion}

Our rapid review identified a total of 40 studies. Low to very low-quality evidence indicated that the proportion of nosocomial infection among confirmed cases of COVID-19 was $44 \%$, which is higher than for SARS but lower than for MERS. Most patients with COVID-19 and SARS infected in hospitals were medical staff, among whom nurses formed the largest group, followed by doctors. Both SARS and MERS outbreaks have been reported in hospitals, but we found no evidence of a COVID-19 outbreak.

SARS-CoV-2, the infectious agent causing COVID-19, is highly contagious, mainly spread by droplets and close 


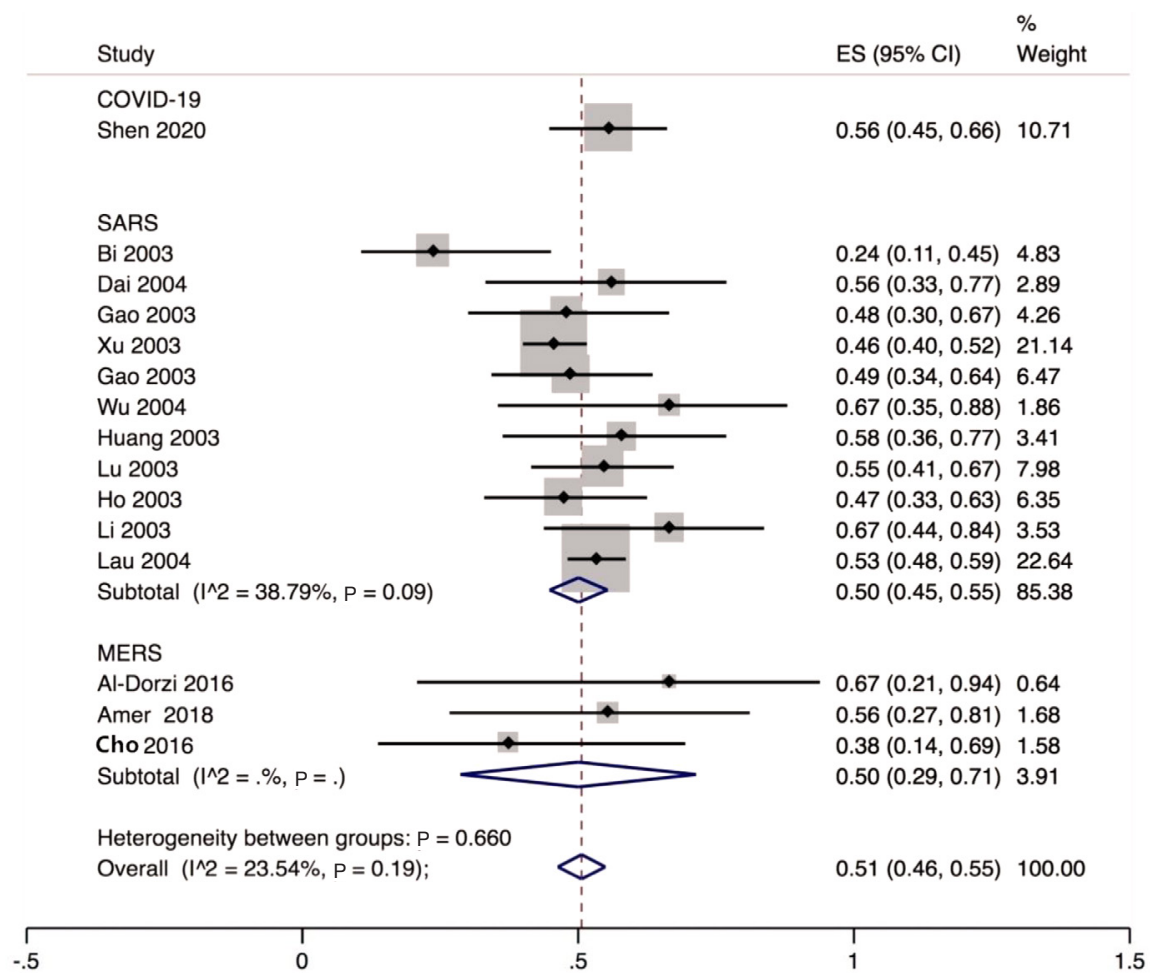

Figure 6 Proportion of nurses among hospital staff with COVID-19, SARS and MERS.

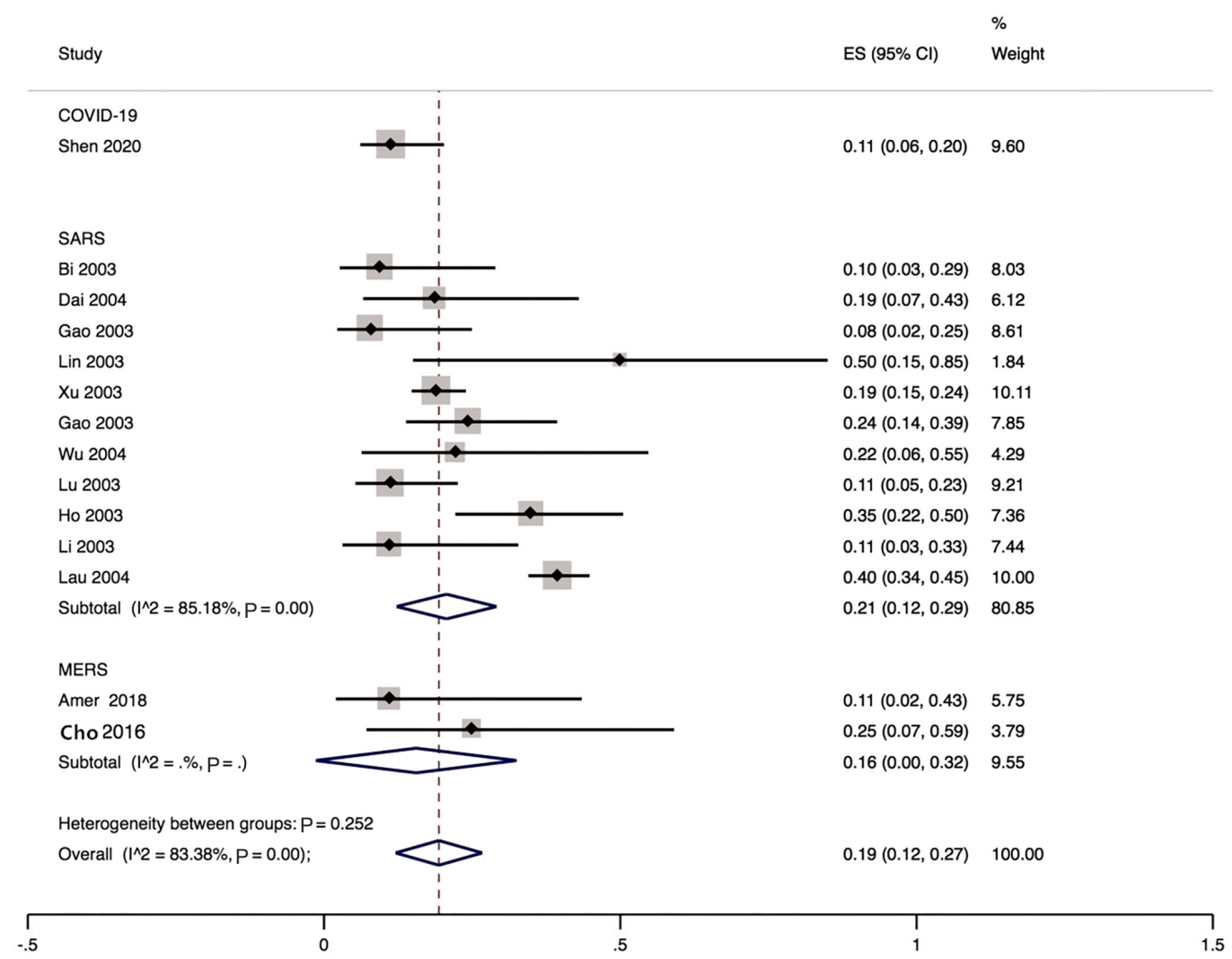

Figure 7 Proportion of staff other than doctors or nurses among hospital staff with COVID-19, SARS and MERS. 


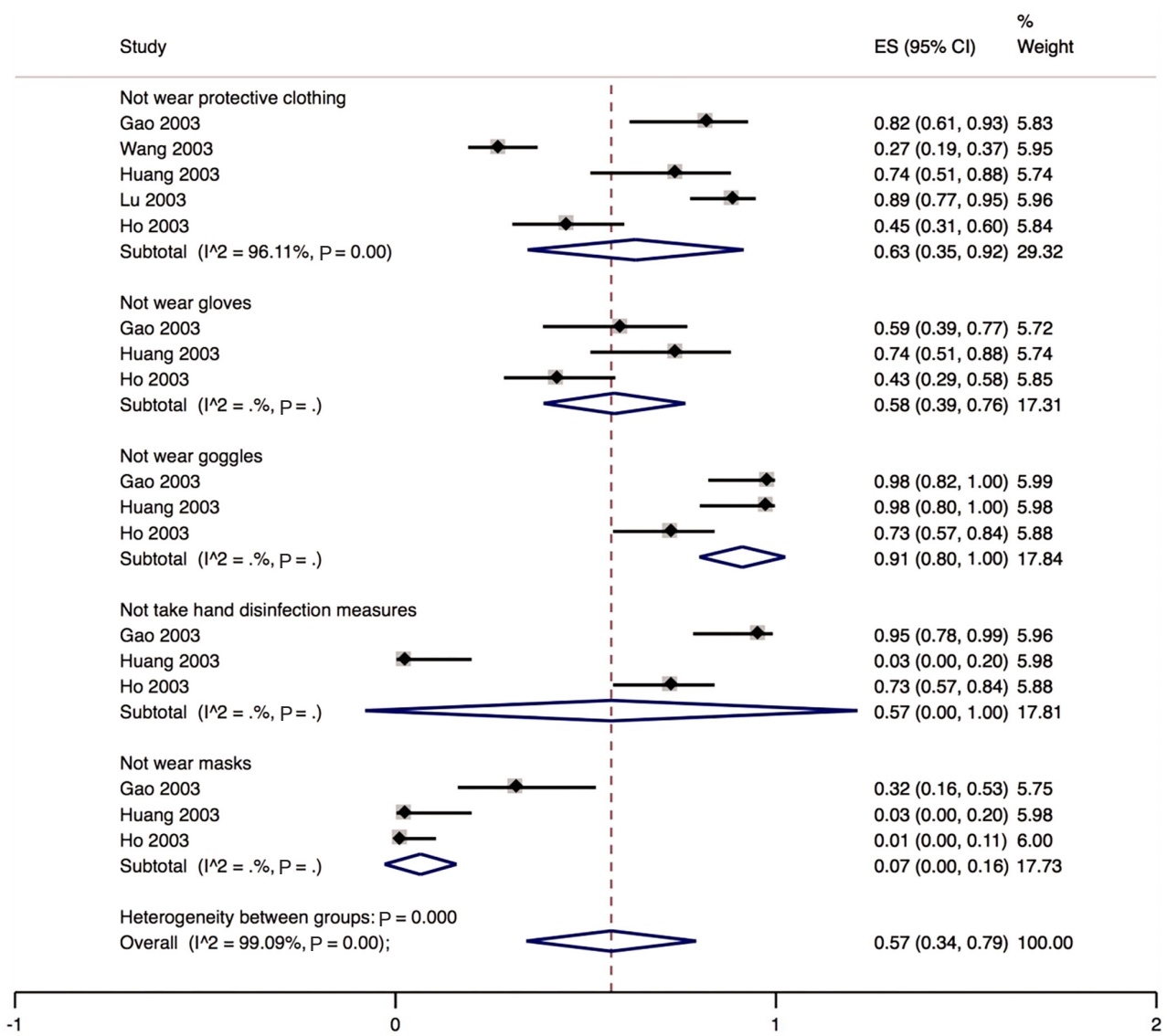

Figure 8 Proportion of health care staff with SARS who did not take protective measures.

Table 2 Secondary infected by index patient in outbreaks in the hospitals

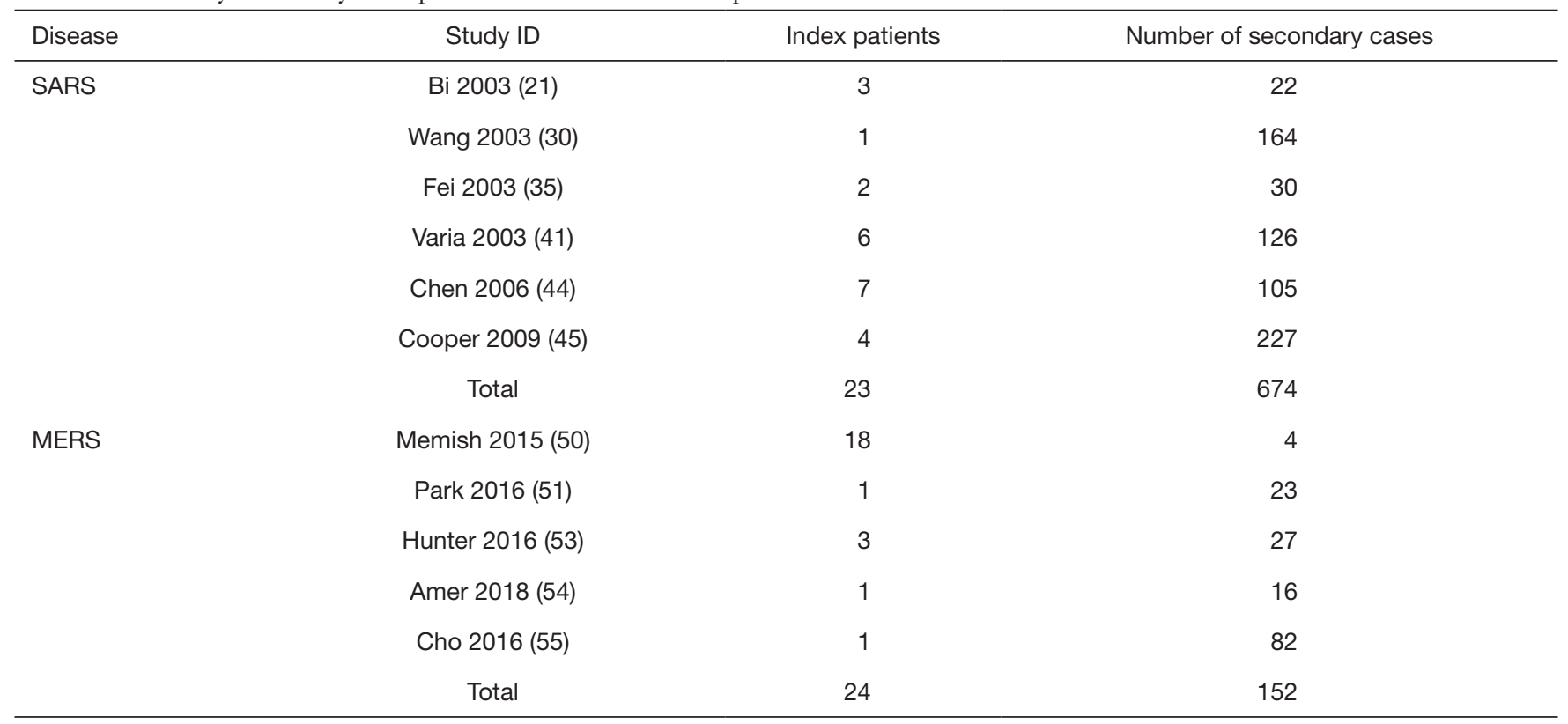


contact. So far, a number of familial disease clusters have been reported, and some of the confirmed patients had been infected in healthcare facilities. As health care workers are in contact with a large number of suspected patients on a daily basis, strict precautions need to be taken to avoid outbreaks of infection in health care facilities. In the early stage of the epidemic, some hospitals, staff or publics did not have enough knowledge about the virus, leading to inadequate prevention and control measures, which may explain the reasons why the proportions of nosocomial infection are high in our study. The proportions may be higher than the real ones because the data of COVID-19 were from the early outbreak in Wuhan. When COVID-19 broke out in Wuhan at the beginning, medical resources were scarce, and various protective measures and management of hospitals were not in place, resulting in a high rate of nosocomial infections. Suspected patients did often not take any protection measures when they went to the hospital, which may have caused nosocomial infections and hospital outbreaks $(19,20)$. A MERS study showed routine infection-prevention policies can greatly reduce nosocomial transmission of MERS (57). According to a report by the WHO, $20 \%$ of confirmed cases of SARS were among health care workers (58). Due to the rapidly evolving outbreak and spread of the disease, medical staff need to work in a state of high tension, but they should also protect themselves adequately and take the appropriate isolation measures to avoid cross infection in the hospital.

The high presence of the COVID-19 epidemic in the media is likely to improve the general public's awareness. People with symptoms indicating a SARS-CoV-2 infection should take protective measures during the hospital or clinic visit, such as wearing a mask, minimizing the time of stay in the hospital, and if possible, making remote medical consultation in advance. Medical institutions should formulate sound infection prevention and control strategies, and strengthen the hospital's infection prevention and control efforts, such as the establishment of special departments for outpatients with fever, and a sound triage system: triage of early identification among suspected cases can avoid excessive gathering of patients in the hospital. Isolation wards should be established for suspected and confirmed patients needing treatment. In hospitals without single isolation wards or negative pressure isolation, indoor ventilation measures should be taken timely, and the management of patients should be standardized in these wards. Using adequate disinfection procedures can reduce the possibility of hospital transmission of the virus. During the epidemic, efforts should be made to publicize the knowledge of infection prevention and control, be alert to the possibility of the outbreak of nosocomial infection, and establish an early warning mechanism. Emergency plans or measures should be developed to deal with nosocomial infections.

\section{Strengths and limitations}

Our study included studies related to nosocomial infections among COVID-19, SARS and MERS patients. Our results can help the decision-making related to prevention, control and clinical management in hospitals. Some studies had missing data, and we used methods of meta-analyses of proportions to analyse those studies with available data, so the proportions estimated may not be accurate and similar to the actual data. Most of the results are based on lowquality research, so that the credibility of the results is low.

\section{Conclusions}

A large proportion of confirmed cases of COVID-19 were infected within healthcare facilities. Therefore, the patients who come to the hospital should do pay attention on personal protection. At the same time, medical institutions can reduce the spread of the virus through triage, and setting up separate fever clinic and isolation wards. Awareness of the disease needs to be improved among medical staff, so that they can protect themselves adequately and stop the spread of the virus within hospitals.

\section{Acknowledgments}

We thank Janne Estill, Institute of Global Health of University of Geneva for providing guidance and comments for our review. We thank all the authors for their wonderful collaboration.

Funding: This work was supported by grants from National Clinical Research Center for Child Health and Disorders (Children's Hospital of Chongqing Medical University, Chongqing, China) (grant number NCRCCHD-2020EP-01) to Enmei Liu; Special Fund for Key Research and Development Projects in Gansu Province in 2020, to Yaolong Chen; The fourth batch of "Special Project of Science and Technology for Emergency Response to COVID-19" of Chongqing Science and Technology Bureau, to Enmei Liu; Special funding for prevention and control of emergency of COVID-19 from Key Laboratory 
of Evidence Based Medicine and Knowledge Translation of Gansu Province (grant number No. GSEBMKT2020YJ01), to YC; The Fundamental Research Funds for the Central Universities (lzujbky-2020-sp14), to YC and $\mathrm{KY}$.

\section{Footnote}

Reporting Checklist: The authors have completed the PRISMA reporting checklist. Available at http://dx.doi. org/10.21037/atm-20-3324

Conflicts of Interest: All authors have completed the ICMJE uniform disclosure form (available at http://dx.doi. org/10.21037/atm-20-3324). MSL serves as the unpaid editorial board member of Annals of Translational Medicine from Nov 2019 to Oct 2021. The other authors have no conflicts of interest to declare.

Ethical Statement: The authors are accountable for all aspects of the work in ensuring that questions related to the accuracy or integrity of any part of the work are appropriately investigated and resolved.

Open Access Statement: This is an Open Access article distributed in accordance with the Creative Commons Attribution-NonCommercial-NoDerivs 4.0 International License (CC BY-NC-ND 4.0), which permits the noncommercial replication and distribution of the article with the strict proviso that no changes or edits are made and the original work is properly cited (including links to both the formal publication through the relevant DOI and the license). See: https://creativecommons.org/licenses/by-nc-nd/4.0/.

\section{References}

1. Huang C, Wang Y, Li X, et al. Clinical features of patients infected with 2019 novel coronavirus in Wuhan, China. Lancet 2020;395:497-506.

2. National Health Commission \& National Administration of Traditional Chinese Medicine. Diagnosis and Treatment Protocol for Novel Coronavirus Pneumonia (Trial Version 7) [J/OL] . Chin Med J,2020,133 (2020-03-13). Available online: http://rs.yiigle.com/yufabiao/1184760.htm. doi: 10.3760/cma.j.issn.0366-6999.2020.0027.

3. Liu Y, Gayle AA, Wilder-Smith A, et al. The reproductive number of COVID-19 is higher compared to SARS coronavirus. J Travel Med 2020;27:taaa021.

4. Khan S, Ali A, Siddique R, et al. Novel coronavirus is putting the whole world on alert. J Hosp Infect 2020;104:252-3.

5. WHO Director-General's opening remarks at the media briefing on COVID-19 - 11 March 2020[Internet]. World Health Organization;c2020 [cited 2020 Apr 13]. Available online: https://www.who.int/dg/speeches/detail/ who-director-general-s-opening-remarks-at-the-mediabriefing-on-covid-19---11-march-2020

6. Coronavirus disease (COVID-19) outbreak situation Data as reported by national authorities by 7 April 2020, 08:00 GMT+8[Internet]. World Health Organization; c2020 [cited 2020 Apr 13]. Available online: https://www.who. int/emergencies/diseases/novel-coronavirus-2019

7. Chan JF, Yuan SF, Kok KH, et al. A familial cluster of pneumonia associated with the 2019 novel coronavirus indicating person-to-person transmission: a study of a family cluster. Lancet 2020;395:514-23.

8. Wang D, Hu B, Hu C, et al. Clinical Characteristics of 138 Hospitalized Patients With 2019 Novel CoronavirusInfected Pneumonia in Wuhan, China. JAMA 2020;323:1061-9.

9. The Novel Coronavirus Pneumonia Emergency Response Epidemiology Team. Vital surveillances: the epidemiological characteristics of an outbreak of 2019 novel coronavirus diseases (COVID-19)—China, 2020. China CDC Weekly. 2020;2:113-22. Available online: http://weekly.chinacdc.cn/en/article/id/e53946e2-c6c441e9-9a9b-fea8db1a8f51

10. Li L, Tian JH, Tian HL, et al. Network meta-analyses could be improved by searching more sources and by involving a librarian. J Clin Epidemiol 2014;67:1001-7.

11. Moher D, Liberati A, Tetzlaff J, et al. Preferred Reporting Items for Systematic Reviews and Meta-Analyses: The PRISMA Statement. PLoS Med 2009;6:e1000097.

12. Wells G, Shea B, O'Connell D, et al. NewCastle-Ottawa Quality Assessment Scale --Cohort Studies. [cited 2020 Mar 31]. Available online: http://www.ohri.ca/programs/ clinical_epidemiology/oxford.asp

13. Rostom A, Dubé C, Cranney A, et al. Celiac Disease. Rockville (MD): Agency for Healthcare Research and Quality (US); 2004 Sep. Evidence Reports/Technology Assessments, No. 104. Appendix D. Quality Assessment Forms. Available online: https://www.ncbi.nlm.nih.gov/ books/NBK35156/

14. National Institute for Health and Care Excellence 2003 [cited 2020 Apr 13] Available online: https://www.nice.org. 
uk/guidance/cg3/documents/appendix-4-quality-of-caseseries-form2

15. Norris SL, Meerpohl JJ, Akl EA, et al. The skills and experience of GRADE methodologists can be assessed with a simple tool. J Clin Epidemiol 2016;79:150-8.e1.

16. Guyatt GH, Oxman AD, Vist GE, et al. GRADE: an emerging consensus on rating quality of evidence and strength of recommendations. BMJ 2008;336:924-6.

17. Ge L, Tian J, Li Y, et al. Association between prospective registration and overall reporting and methodological quality of systematic reviews: a meta-epidemiological study. J Clin Epidemiol 2018;93:45-55.

18. Wang Q, Kuang W, Ping W, et al. Prevention and treatment of cross infection of novel coronavirus pneumonia in thoracic surgery ward. Chin J Thoracic Cardiovasc Surg 2020;27:371-5.

19. Jiang $W$, Lu Z, Shen X, et al. Clinical practice of prevention and treatment of novel coronavirus infection in the medical personnel and surgical patients in the Department of Thoracic Surgery of Hospitals in Wuhan. Chin J Thoracic Cardiovasc Surg 2020;27:364-70.

20. Shen Y, Ke C, Yang C, et al. A case-control study on 2019-nCov infection-related factors among medical staff in Wuhan Tongji Hospital. Chin J Nosocomiology 2020;30:1157-60.

21. Bi X, Zhou F, Zhang K. A cluster of cases of infectious SARS in a hospital. Chin J Resp Crit Care Med 2003;2:161-3.

22. Dai L, Gao Y, Zeng W. Epidemiological investigation of nosocomial infection of SARS in a Chinese medicine hospital in Guangdong Province. Chin J Public Health Management 2004;20:242.

23. Zou Q, Lin WS, Du L. An investigation on nosocomial infection with severe acute respiratory syndrome in healthcare workers at 13 key hospitals in Guangdong Province. Zhonghua Liu Xing Bing Xue Za Zhi 2004;38:87-9.

24. Wang M, Du L, Zhou D, et al. Study on the epidemiology and measures for control on severe acute respiratory syndrome in Guangzhou city. Zhonghua Liu Xing Bing Xue Za Zhi 2003;24:353-7.

25. Gao L, Zhang X, Yin W. Investigation and analysis of nosocomial infection of SARS among medical staff in a hospital in Guangzhou. South Chin J Prevent Med 2003;29:19-20.

26. Lin W, Yin W, Zhou Q. Analysis of the effect of the preventive measures against SARS infection in a hospital in Guangzhou. South Chin J Prevent Med 2003;29:17-8.

27. Xu H, Wang M, Liu Y. SARS outbreak and control in hospital health care workers in Guangzhou. South Chin J Prevent Med 2003;29:16-8.

28. Gao X, Chang A, Yang Z. Analysis of communicated severe acute respiratory syndrome in staff of a general hospital. J Logistics U Capf 2003;12:424-7.

29. Yuan J, Hu Y, Jiang X. Epidemiological Analysis on Severe Acute Respiratory Syndrome in Shenzhen city. J Tropical Med 2003;3:423-4, 83.

30. Wang JX, Feng H, Liu D. Epidemiological characteristics of severe acute respiratory syndrome in Tianjin and the assessment of effectiveness on measures of control. Zhonghua Liu Xing Bing Xue Za Zhi 2003;24:565-9.

31. Wang G, Zhao W, Zhang F. The causes and control strategies of epidemic severe acute respiratory syndrome in hospitals. Chin J Infect Control 2003;2:165-7.

32. Wu J, Li L, Xu Y. Role of Hospital Infection Control System in Decreasing SARS Infection among Medical Staff. Chin J Nosocomiology 2004;14:903-5.

33. Huang L, Zhang S, Yin C. Analysing Causes and Preventive Measures of Occurring SARS among Medical Workers. Chin J Nosocomiology 2003;13:1050-2.

34. Li G, Gu Y, Liang H. Epidemiological analysis on SARS cases in Zhongshan.South Chin J Prevent Med 2003;29:42-3.

35. Fei Y, He Y, Liu D. Study and evaluation on the measures of prevention and control in SARS hospital infection. J Chin PLA Postgraduate Medical School 2003;24:304-6.

36. Lu H, Huo N, Xu X. The epidemiological characteristics of patients with Severe Acute Respiratory Syndrome (SARS). Beijing Da Xue Xue Bao Yi Xue Ban 2003;35:8-11.

37. He X,Liu Z, Ma Y, et al. Epidemic characteristics of SARS in Beijing in 2003. Xiangshan Science Meeting, 2003.

38. Ho AS, Sung JJ, Chan-Yeung M. An outbreak of severe acute respiratory syndrome among hospital workers in a community hospital in Hong Kong. Ann Intern Med 2003;139:564-7.

39. Li L, Cheng S, Gu J. Analysis of medical workers suffered from SARS. Beijing Da Xue Xue Bao Yi Xue Ban 2003;35:51-4.

40. Fowler RA, Lapinsky SE, Hallett D, et al. Critically Ill Patients with Severe Acute Respiratory Syndrome. JAMA 2003;290:367-73.

41. Varia M, Wilson S, Sarwal S, et al. Investigation of a nosocomial outbreak of severe acute respiratory syndrome (SARS) in Toronto, Canada. CMAJ 2003;169:285-92.

42. Lau JTF, Yang X, Leung PC, et al. SARS in three categories of hospital workers, Hong Kong. Emerg Infect Dis 2004;10:1399-404. 
43. Zhou Y, Chen S, Gao Y. Protective Measures to Medical Personnel and Their Effectiveness in SARS Prevention During the SARS Outbreak in Guangdong Province. Chin J Nosocomiology 2004;14:433-5.

44. Chen M, Leo YS, Ang B, et al. The outbreak of SARS at Tan Tock Seng Hospital--relating epidemiology to control. Ann Acad Med Singapore. 2006;35:317-25.

45. Cooper BS, Fang LQ, Zhou JP, et al. Transmission of SARS in three Chinese hospitals. Trop Med Int Health 2009;14 Suppl 1:71-8.

46. Oboho IK, Tomczyk SM, Al-Asmari AM, et al. 2014 MERS-CoV outbreak in Jeddah-a link to health care facilities. N Engl J Med 2015;372:846-54.

47. Xiang N, Lin D, An G. Epidemiological characteristics of Middle East Respiratory Syndrome outbreak in the Republic of Korea, 2015. Zhonghua Liu Xing Bing Xue Za Zhi 2015;36:836-41.

48. Assiri A, McGeer A, Perl TM, et al. Hospital outbreak of Middle East respiratory syndrome coronavirus. N Engl J Med 2013;369:407-16.

49. Alenazi TH, Al Arbash H, El-Saed A, et al. Identified Transmission Dynamics of Middle East Respiratory Syndrome Coronavirus Infection During an Outbreak: Implications of an Overcrowded Emergency Department. Clin Infect Dis 2017;65:675-9.

50. Memish ZA, Al-Tawfiq JA, Alhakeem RF, et al. Middle East respiratory syndrome coronavirus (MERS-CoV): A cluster analysis with implications for global management of suspected cases. Travel Med Infect Dis 2015;13:311-4.

51. Park SH, Kim Y, Jung Y, et al. Outbreaks of middle east respiratory syndrome in two hospitals initiated by a single patient in Daejeon, South Korea. Infect Chemother

Cite this article as: Zhou Q, Gao Y, Wang X, Liu R, Du P, Wang X, Zhang X, Lu S, Wang Z, Shi Q, Li W, Ma Y, Luo X, Fukuoka T, Ahn HS, Lee MS, Liu E, Chen Y, Luo Z, Yang K; on behalf of COVID-19 Evidence and Recommendations Working Group. Nosocomial infections among patients with COVID-19, SARS and MERS: a rapid review and meta-analysis. Ann Transl Med 2020;8(10):629. doi: 10.21037/atm-20-3324
2016;48:99-107.

52. Al-Dorzi HM, Aldawood AS, Khan R, et al. The critical care response to a hospital outbreak of Middle East respiratory syndrome coronavirus (MERS-CoV) infection: an observational study. Ann Intensive Care 2016;6:101.

53. Hunter JC, Nguyen D, Aden B, et al. Transmission of Middle East Respiratory Syndrome Coronavirus Infections in Healthcare Settings, Abu Dhabi. Emerg Infect Dis 2016;22:647-56.

54. Amer H, Alqahtani AS, Alzoman H, et al. Unusual presentation of Middle East respiratory syndrome coronavirus leading to a large outbreak in Riyadh during 2017. Am J Infect Control 2018;46:1022-5.

55. Cho SY, Kang JM, Ha YE, et al. MERS-CoV outbreak following a single patient exposure in an emergency room in South Korea: an epidemiological outbreak study. Lancet 2016;388:994-1001.

56. Hijawi B, Abdallat M, Sayaydeh A, et al. Novel coronavirus infections in Jordan, April 2012: epidemiological findings from a retrospective investigation. East Mediterr Health J 2013;19 Suppl 1:S12-8.

57. Ki HK, Han SK, Son JS, et al. Risk of transmission via medical employees and importance of routine infectionprevention policy in a nosocomial outbreak of Middle East respiratory syndrome (MERS): a descriptive analysis from a tertiary care hospital in South Korea. BMC Pulm Med 2019;19:190.

58. Summary table of SARS cases by country, 1 November 2002 - 7 August 2003 [Internet]. World Health Organization; c2020 [cited 2020 Apr 13]. Available online: https://www.who.int/csr/sars/country/ country2003_08_15.pdf?ua=1 


\section{Search strategy}

\section{PubMed}

\#1 “COVID-19”[Supplementary Concept]

\#2 "Severe Acute Respiratory Syndrome Coronavirus 2"[Supplementary Concept]

\#3 "Middle East Respiratory Syndrome Coronavirus"[Mesh]

\#4 "Severe Acute Respiratory Syndrome"[Mesh]

\#5 "SARS Virus"[Mesh]

\#6 “COVID-19"[Title/Abstract]

\#7 "SARS-COV-2"[Title/Abstract]

\#8 "Novel coronavirus"[Title/Abstract]

\#9 “2019-novel coronavirus"[Title/Abstract]

\#10 “coronavirus disease-19"[Title/Abstract]

\#11 “coronavirus disease 2019”[Title/Abstract]

\#12 “COVID19"[Title/Abstract]

\#13 "Novel CoV"[Title/Abstract]

\#14 "2019-nCoV"[Title/Abstract]

\#15 “2019-CoV”[Title/Abstract]

\#16 "Middle East Respiratory Syndrome"[Title/Abstract]

\#17 “MERS"[Title/Abstract]

\#18 "MERS-CoV"[Title/Abstract]

\#19 "Severe Acute Respiratory Syndrome"[Title/Abstract]

\#20 "SARS"[Title/Abstract]

\#21 "SARS-CoV"[Title/Abstract]

\#22 "SARS-Related"[Title/Abstract]

\#23 “SARS-Associated"[Title/Abstract]

\#24 \#1-\#23/OR

\#25 “Cross Infection"[MeSH Terms]

\#26 "Cross Infection*"[Title/Abstract]

\#27 "Healthcare Associated Infections"”[Title/Abstract]

\#28 "Health Care Associated Infection*"[Title/Abstract]

\#29 "Hospital Infection"”[Title/Abstract]

\#30 “Nosocomial Infection*”[Title/Abstract]

\#31 "hospital-related infection*"[Title/Abstract]

\#32 "hospital-acquired infection*"[Title/Abstract]

\#33 \#25-\#32/OR

\#34 \#24 AND \#33

\section{Embase}

\#1 'middle east respiratory syndrome coronavirus'/exp

\#2 'severe acute respiratory syndrome'/exp

\#3 'sars coronavirus'/exp

\#4 'COVID-19':ab,ti

\#5 'SARS-COV-2':ab,ti

\#6 'novel coronavirus':ab,ti

\#7 '2019-novel coronavirus':ab,ti
\#8 'coronavirus disease-19':ab,ti

\#9 'coronavirus disease 2019':ab,ti

\#10 'COVID19':ab,ti

\#11 'novel cov':ab,ti

\#12 '2019-ncov':ab,ti

\#13 '2019-cov':ab,ti

\#14 'middle east respiratory syndrome':ab,ti

\#15 'middle east respiratory syndrome coronavirus':ab,ti

\#16 'mers':ab,ti

\#17 'mers-cov':ab,ti

\#18 'severe acute respiratory syndrome':ab,ti

\#19 'sars':ab,ti

\#20 'sars-cov':ab,ti

\#21 'sars-related':ab,ti

\#22 'sars-associated':ab,ti

\#23 \#1-\#22/OR

\#24 'hospital infection*':ab,ti

\#25 'nosocomial infection*':ab,ti

\#26 'hospital-related infection*':ab,ti

\#27 'hospital-acquired infection*':ab,ti

\#28 'cross infection*':ab,ti

\#29 'healthcare associated infection"':ab,ti

\#30 'health care associated infection*':ab,ti

\#31 \#24-\#30/OR

\#32 23 AND \#31

Web of Science

\#1 TOPIC: "COVID-19"

\#2 TOPIC: "SARS-COV-2"

\#3 TOPIC: "Novel coronavirus"

\#4 TOPIC: "2019-novel coronavirus"

\#5 TOPIC: "coronavirus disease-19"

\#6 TOPIC: "coronavirus disease 2019"

\#7 TOPIC: "COVID 19"

\#8 TOPIC: "Novel CoV"

\#9 TOPIC: "2019-nCoV"

\#10 TOPIC: "2019-CoV"

\#11 TOPIC: "Middle East Respiratory Syndrome"

\#12 TOPIC: "MERS"

\#13 TOPIC: "MERS-CoV"

\#14 TOPIC: "Severe Acute Respiratory Syndrome"

\#15 TOPIC: "SARS"

\#16 TOPIC: "SARS-CoV"

\#17 TOPIC: "SARS-Related"

\#18 TOPIC: "SARS-Associated"

\#19 \#1-\#18/OR

\#20 TITLE: "Healthcare Associated Infection"

\#21 TITLE: "Healthcare Associated Infections" 
\#22 TITLE: "Health Care Associated Infection"

\#23 TITLE: "Health Care Associated Infections"

\#24 TITLE: "Hospital Infection"

\#25 TITLE: "Nosocomial Infection"

\#26 TITLE: "Nosocomial Infections"

\#27 TITLE: "Hospital Infections"

\#28 TITLE: "hospital-related infection"

\#29 TITLE: "hospital-acquired infection"

\#30 TITLE: "Cross Infection"

\#31 TITLE: "Cross Infections"

\#32 \#20-\#31/OR

\#33 \#19 AND \#32

\section{Cochrane Library}

\#1 MeSH descriptor: [Middle East Respiratory Syndrome Coronavirus] explode all trees

\#2 MeSH descriptor: [Severe Acute Respiratory Syndrome] explode all trees

\#3 MeSH descriptor: [SARS Virus] explode all trees

\#4 “COVID-19":ti,ab,kw

\#5 "SARS-COV-2":ti,ab,kw

\#6 “Novel coronavirus":ti,ab,kw

\#7 “2019-novel coronavirus”:ti,ab,kw

\#8 "Novel CoV":ti,ab,kw

\#9 “2019-nCoV":ti,ab,kw

\#10 “2019-CoV”:ti,ab,kw

\#11 “coronavirus disease-19”:ti,ab,kw

\#12 “coronavirus disease 2019”:ti,ab,kw

\#13 “COVID19”:ti,ab,kw

\#14 "Middle East Respiratory Syndrome":ti,ab,kw

\#15 “MERS":ti,ab,kw

\#16 "MERS-CoV":ti,ab,kw

\#17 “Severe Acute Respiratory Syndrome”:ti,ab,kw

\#18 “SARS":ti,ab,kw

\#19 “SARS-CoV”:ti,ab,kw

\#20 “SARS-Related":ti,ab,kw

\#21 "SARS-Associated":ti,ab,kw

\#22 \#1-\#21/OR

\#23 “hospital-related infection"”:ti,ab,kw

\#24 "hospital-related infection*":ti,ab,kw

\#25 “cross infection*":ti,ab,kw

\#26 "healthcare associated infection*":ti,ab,kw

\#27 "health care associated infection*":ti,ab,kw

\#28 "hospital infection*":ti,ab,kw

\#29 "nosocomial infection*”:ti,ab,kw

\#30 \#23-\#29/OR

\#31 \#22 AND \#30

\section{CNKI}

\#1 “新型冠状病毒”[主题]

\#2 “COVID-19”[主题]

\#3“COVID 19”[主题]

\#4 “2019-nCoV”[主题]

\#5 “2019-CoV”[主题]

\#6 “SARS-CoV-2”[主题]

\#7 “中东呼吸综合征”[主题]

\#8 “MERS”[主题]

\#9 “MERS-CoV”[主题]

\#10 “严重急性呼吸综合征”[主题]

\#11 “SARS”[主题]

\#12 \#1-\#11/ OR

\#13 “医院相关感染” [主题]

\#14 “医院获得性感染” [主题]

\#15 “医疗机构相关感染” [主题]

\#16 “院内感染” [主题]

\#17 “交叉感染” [主题]

\#18 \#13-\#17/ OR

\#19 \#12 AND \#18

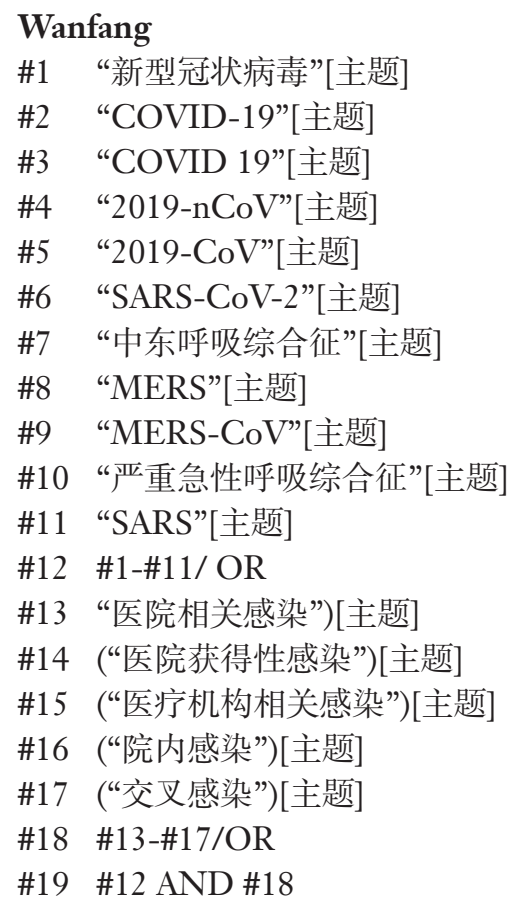

\section{CBM}

\#1 “新型冠状病毒”[常用字段:智能]

\#2 “COVID-19”[常用字段:智能]

\#3 “COVID 19”[常用字段:智能]

\#4 “2019-nCoV”[常用字段:智能] 
\#5 “2019-CoV”[常用字段:智能]

\#6 “SARS-CoV-2”[常用字段:智能]

\#7 “中东呼吸综合征冠状病毒”[不加权:扩展]

\#8 “中东呼吸综合征”[常用字段:智能]

\#9 “MERS”[常用字段:智能]

\#10 “MERS-CoV”[常用字段:智能]

\#11 “严重急性呼吸综合征”[不加权:扩展]

\#12 “SARS病毒”[不加权:扩展]

\#13 “严重急性呼吸综合征”[常用字段:智能]
\#14 “SARS”[常用字段:智能]

\#15 \#1-\#14/OR

\#16 “医院相关感染”[常用字段:智能]

\#17 “医院获得性感染”[常用字段:智能]

\#18 “医疗机构相关感染”[常用字段:智能]

\#19 “交叉感染”[常用字段:智能]

\#20 “院内感染"[常用字段:智能]

\#21 \#16-\#20/OR

\#22 \#15 AND \#21 


\section{Risk of bias in the included studies}

Table S1 Cross-sectional studies

\begin{tabular}{|c|c|c|c|c|c|c|c|c|c|c|c|c|c|}
\hline Study ID & Disease & Item 1 & Item 2 & Item 3 & Item 4 & Item 5 & Item 6 & Item 7 & Item 8 & Item 9 & Item 10 & Item 11 & Scores $^{\dagger}$ \\
\hline Dai 2004 (22) & SARS & Yes & Yes & Yes & No & No & No & No & No & No & No & No & 3 \\
\hline Zou 2004 (23) & SARS & Yes & Yes & Yes & Yes & No & No & No & No & No & Yes & No & 5 \\
\hline Wang 2003 (24) & SARS & Yes & Yes & Yes & Yes & Yes & Yes & No & No & No & No & No & 6 \\
\hline Gao 2003 (25) & SARS & Yes & No & Yes & No & No & No & No & No & No & No & No & 2 \\
\hline Lin 2003 (26) & SARS & Yes & No & Yes & No & No & Yes & No & No & No & No & No & 3 \\
\hline Xu 2003 (27) & SARS & Yes & Yes & Yes & Yes & No & No & No & No & No & Yes & Yes & 6 \\
\hline Gao 2003 (28) & SARS & Yes & Yes & Yes & No & No & No & No & No & No & No & No & 3 \\
\hline Yuan 2003 (29) & SARS & Yes & Yes & Yes & No & No & No & No & No & No & No & No & 3 \\
\hline Wang 2003 (30) & SARS & Yes & Yes & Yes & Yes & No & Yes & No & No & No & No & No & 5 \\
\hline Wang 2003 (31) & SARS & Yes & No & No & No & No & No & No & No & No & No & No & 1 \\
\hline Wu 2004 (32) & SARS & Yes & No & Yes & No & No & No & No & No & No & No & No & 2 \\
\hline Huang 2003 (33) & SARS & Yes & Yes & Yes & Yes & No & No & No & No & No & No & No & 4 \\
\hline Li 2003 (34) & SARS & Yes & Yes & Yes & No & No & No & No & No & No & No & No & 3 \\
\hline Fei 2003 (35) & SARS & Yes & No & Yes & Yes & No & No & No & No & No & No & No & 3 \\
\hline He 2003 (37) & SARS & Yes & Yes & No & Yes & Yes & Yes & Yes & No & No & Yes & No & 7 \\
\hline Ho 2003 (38) & SARS & Yes & Yes & Yes & Yes & Yes & Yes & No & No & No & No & No & 6 \\
\hline Li 2003 (39) & SARS & Yes & Yes & Yes & No & No & No & No & No & No & No & No & 3 \\
\hline Varia 2003 (41) & SARS & Yes & Yes & Yes & Yes & No & No & No & No & No & No & No & 4 \\
\hline Lau 2004 (42) & SARS & Yes & Yes & Yes & Yes & No & No & No & No & No & No & No & 4 \\
\hline Zhou 2004 (43) & SARS & Yes & Yes & Yes & Yes & Yes & No & No & Yes & No & No & No & 6 \\
\hline Chen 2006 (44) & SARS & Yes & Yes & Yes & Yes & No & No & No & No & No & No & No & 4 \\
\hline Cooper 2009 (45) & SARS & Yes & Yes & Yes & Yes & No & No & No & No & No & No & No & 4 \\
\hline Oboho 2015 (46) & MERS & Yes & Yes & No & Yes & Yes & Yes & No & Yes & No & Yes & No & 7 \\
\hline Xiang 2015 (47) & MERS & Yes & Yes & Yes & Yes & Yes & No & No & Yes & No & No & No & 6 \\
\hline Alenazi 2017 (49) & MERS & Yes & Yes & Yes & Yes & No & No & No & No & No & No & No & 4 \\
\hline Memish 2015 (50) & MERS & Yes & Yes & Yes & Yes & Yes & No & No & No & No & No & No & 5 \\
\hline Park 2016 (51) & MERS & Yes & Yes & Yes & Yes & Yes & Yes & No & No & No & No & No & 6 \\
\hline Hunter 2016 (53) & MERS & Yes & Yes & Yes & Yes & Yes & No & No & No & No & No & No & 5 \\
\hline Amer 2018 (54) & MERS & Yes & Yes & Yes & Yes & Yes & Yes & No & No & No & No & No & 6 \\
\hline Hijawi 2013 (56) & MERS & Yes & Yes & Yes & No & No & No & No & No & No & No & No & 3 \\
\hline \multicolumn{14}{|c|}{$\begin{array}{l}\text { ', according to the methodology evaluation tool recommended by the Agency for Healthcare Research and Quality. This tool assesses the } \\
\text { quality of bias according to } 11 \text { criteria. And each criterion is answered by "Yes", "No" or "unsure". The results were summarized by scoring } \\
\text { method, for the "Yes" items, the score was } 1 \text {, and for the "no" items, the score was } 0 \text {. The maximum score is } 11 \text {; the higher the score, } \\
\text { the lower the risk of bias. The numbers } 1 \text { to } 11 \text { refer to the items of the tool: } 1 \text {. defining the source of information (survey, record review); } \\
\text { 2. listing the inclusion and exclusion criteria for exposed and unexposed subjects or referring to previous publications; } 3 \text {. indicate time } \\
\text { period used for identifying patients; } 4 \text {. indicating whether the subjects were recruited consecutively (if not population-based); } 5 \text {. indicating } \\
\text { if evaluators of subjective components of the study were masked from the participants; } 6 \text {. description of any assessments undertaken } \\
\text { for quality assurance purposes (e.g., test/retest of primary outcome measurements); } 7 \text {. explaining any exclusions of patients from the } \\
\text { analysis; } 8 \text {. description how confounding was assessed and/or controlled; } 9 \text {. if applicable, explaining how missing data were handled in } \\
\text { the analysis; } 10 \text {. summarizing patient response rates and completeness of data collection; } 11 \text {. clarification of the expected follow-up (if } \\
\text { any), and the percentage of patients with incomplete data or follow-up. }\end{array}$} \\
\hline
\end{tabular}


Table S2 Case series

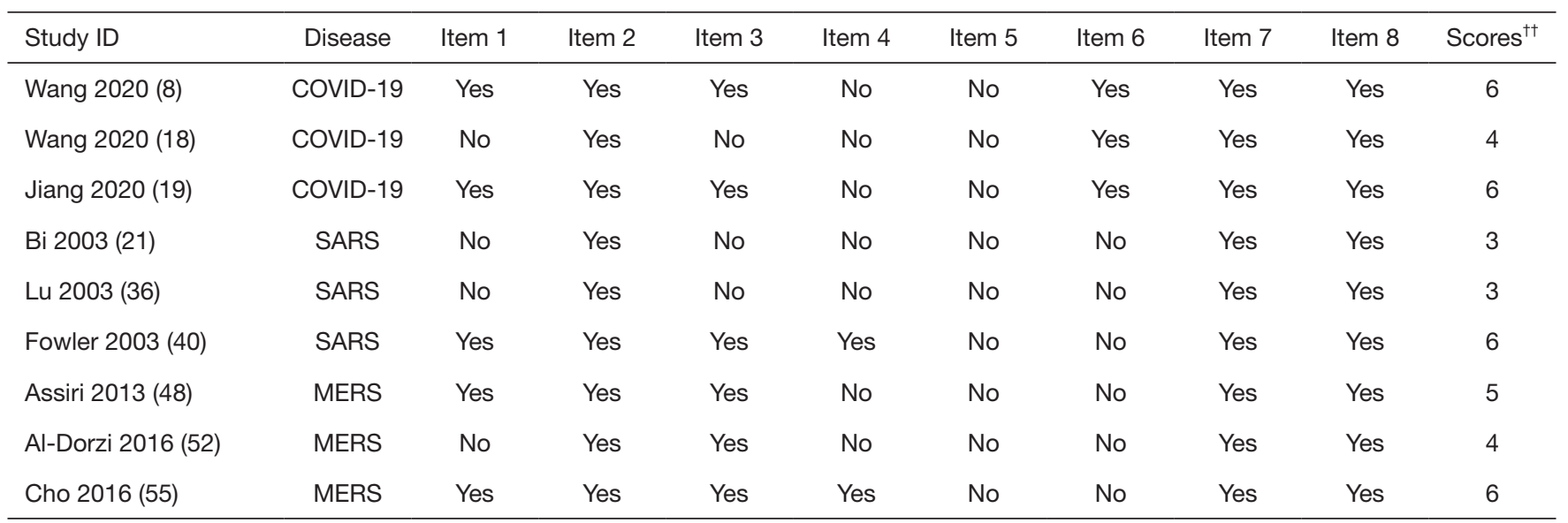

${ }^{+\dagger}$, according to the methodology evaluation tool recommended by National Institute for Health and Care Excellence. The risk of bias is evaluated according to eight criteria. The results were summarized by scoring method, for the "Yes" items, the score was 1 , and for the "no" items, the score was 0 . The maximum score is 8 ; the higher the score, the lower the risk of bias. The numbers 1 to 8 refer to the items of the tool: 1 . case series collected in more than one centre, i.e., multi-centre study; 2 . is the hypothesis/aim/objective of the study clearly described? 3. are the inclusion and exclusion criteria (case definition) clearly reported? 4 . is there a clear definition of the outcomes reported? 5. were data collected prospectively? 6. is there an explicit statement that patients were recruited consecutively? 7. are the main findings of the study clearly described? 8. are outcomes stratified? (e.g., by disease stage, abnormal test results, patient characteristics).

Table S3 Case control study

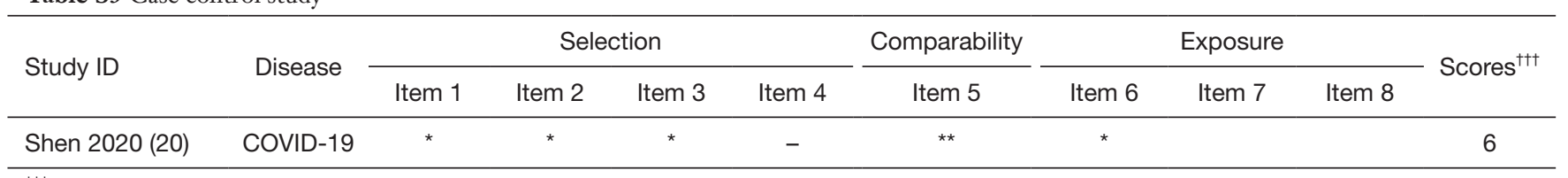

\footnotetext{
${ }^{t+t}$, according to the methodology evaluation tool of Newcastle-Ottawa Scale. It consists of eight domains, for each, we will grade with stars. The more stars, the lower the risk of bias. The maximum score is 9. A study can be awarded a maximum of one star for each numbered item within the Selection and Exposure categories. A maximum of two stars can be given for Comparability. The numbers 1 to 8 refer to the items of the tool: 1. representativeness of the exposed cohort; 2. selection of the non-exposed cohort; 3 . ascertainment of exposure; 4. demonstration that outcome of interest was not present at start of study; 5 . comparability of cohorts on the basis of the design or analysis; 6. assessment of outcome; 7. was follow-up long enough for outcomes to occur; 8 . adequacy of follow up of cohorts.
} 
Summary of findings

Table S4 Summary of findings

\begin{tabular}{|c|c|c|c|c|c|c|c|c|c|}
\hline \multirow{2}{*}{ Outcomes } & \multirow{2}{*}{$\begin{array}{l}\text { No. of } \\
\text { studies }\end{array}$} & \multirow{2}{*}{$\begin{array}{l}\text { Sample } \\
\text { size }\end{array}$} & \multicolumn{5}{|c|}{ Certainty assessment } & \multirow{2}{*}{$\begin{array}{c}\text { Effect value } \\
(95 \% \mathrm{Cl})\end{array}$} & \multirow{2}{*}{ Certainty } \\
\hline & & & Risk of bias & Inconsistency & Indirectness & Imprecision & Other considerations & & \\
\hline Nosocomial infections among confirm cases of COVID-19 & 2 & 179 & Serious $^{1}$ & Not serious & Not serious & Serious $^{3}$ & None & $44 \%(36 \%, 51 \%)$ & $\oplus \oplus \circ \bigcirc$ low \\
\hline Nosocomial infections among confirm cases of SARS & 6 & 3,610 & Serious ${ }^{1}$ & Serious $^{2}$ & Not serious & Not serious & None & $36 \%(23 \%, 49 \%)$ & $\oplus \oplus \circ \bigcirc$ low \\
\hline Nosocomial infections among confirm cases of MERS & 6 & 1,049 & Serious ${ }^{1}$ & Serious $^{2}$ & Not serious & Serious $^{3}$ & None & $56 \%(8 \%, 100 \%)$ & $\oplus \circ \bigcirc \bigcirc$ very low \\
\hline Health care workers among confirmed cases of COVID- 19 & 2 & 179 & Serious ${ }^{1}$ & Not serious & Not serious & Serious $^{4}$ & None & $33 \%(27 \%, 40 \%)$ & $\oplus \oplus \circ \bigcirc$ low \\
\hline Health care workers among confirmed cases of SARS & 6 & 3,662 & Serious ${ }^{1}$ & Serious $^{2}$ & Not serious & Not serious & None & $37 \%(25 \%, 49 \%)$ & $\oplus \oplus \circ \bigcirc$ low \\
\hline Health care workers among confirmed cases of MERS & 6 & 1,049 & Serious $^{1}$ & Serious $^{2}$ & Not serious & Not serious & None & $19 \%(4 \%, 35 \%)$ & $\oplus \oplus \circ \bigcirc$ low \\
\hline Excluding health care workers among confirm cases of COVID-19, SARS and MERS & 2 & 589 & Serious ${ }^{1}$ & Not serious & Not serious & Serious $^{4}$ & None & $2 \%(1 \%, 3 \%)$ & $\oplus \oplus \circ \bigcirc$ low \\
\hline Excluding health care workers among confirm cases of SARS & 4 & 267 & Serious $^{1}$ & Serious $^{2}$ & Not serious & Serious $^{4}$ & None & $24 \%(10 \%, 38 \%)$ & $\oplus \circ \bigcirc \bigcirc$ very low \\
\hline Excluding health care workers among confirm cases of MERS & 6 & 1,049 & Serious ${ }^{1}$ & Serious $^{2}$ & Not serious & Serious $^{3}$ & None & $36 \%(6 \%, 67 \%)$ & $\oplus \circ \bigcirc \bigcirc$ very low \\
\hline Doctors among hospital staff with COVID-19 & 1 & 79 & Serious $^{1}$ & Not serious & Not serious & Serious $^{4}$ & None & $33 \%(24 \%, 44 \%)$ & $\oplus \oplus \circ \bigcirc$ low \\
\hline Doctors among hospital staff with SARS & 12 & 865 & Serious ${ }^{1}$ & Serious $^{2}$ & Not serious & Serious $^{4}$ & None & $30 \%(19 \%, 40 \%)$ & $\oplus \circ 0 \bigcirc$ very low \\
\hline Doctors among hospital staff with MERS & 3 & 20 & Serious ${ }^{1}$ & Not serious & Not serious & Serious $^{3}$ & None & $35 \%(14 \%, 56 \%)$ & $\oplus \oplus \circ \bigcirc$ low \\
\hline Nurses among hospital staff with COVID-19 & 1 & 79 & Serious $^{1}$ & Not serious & Not serious & Serious $^{4}$ & None & $56 \%(45 \%, 66 \%)$ & $\oplus \oplus \bigcirc \bigcirc$ low \\
\hline Nurses among hospital staff with SARS & 11 & 861 & Serious $^{1}$ & Not serious & Not serious & Serious ${ }^{4}$ & None & $50 \%(45 \%, 55 \%)$ & $\oplus \oplus \circ \bigcirc$ low \\
\hline Nurses among hospital staff with MERS & 3 & 20 & Serious $^{1}$ & Not serious & Not serious & Serious $^{3}$ & None & $50 \%(29 \%, 71 \%)$ & $\oplus \oplus \circ \circ$ low \\
\hline Staff other than doctors or nurses among hospital staff with COVID-19 & 1 & 79 & Serious ${ }^{1}$ & Not serious & Not serious & Serious $^{4}$ & None & $11 \%(6 \%, 20 \%)$ & $\oplus \oplus \circ \bigcirc$ low \\
\hline Staff other than doctors or nurses among hospital staff with SARS & 11 & 846 & Serious $^{1}$ & Serious ${ }^{2}$ & Not serious & Serious ${ }^{4}$ & None & $21 \%(12 \%, 29 \%)$ & $\oplus \circ \bigcirc \bigcirc$ very low \\
\hline Staff other than doctors or nurses among hospital staff with MERS & 2 & 17 & Serious $^{1}$ & Not serious & Not serious & Serious $^{4}$ & None & $16 \%(0 \%, 32 \%)$ & $\oplus \oplus \bigcirc \bigcirc$ low \\
\hline Health care staff with SARS who did not wear protective clothing & 5 & 222 & Serious ${ }^{1}$ & Serious $^{2}$ & Not serious & Serious $^{4}$ & None & $63 \%(35 \%, 92 \%)$ & $\oplus \circ \bigcirc \bigcirc$ very low \\
\hline Health care staff with SARS who did not wear gloves & 3 & 81 & Serious $^{1}$ & Not serious & Not serious & Serious $^{3}$ & None & $58 \%(39 \%, 76 \%)$ & $\oplus \oplus \circ \bigcirc$ low \\
\hline Health care staff with SARS who did not wear goggles & 3 & 81 & Serious $^{1}$ & Not serious & Not serious & Serious $^{4}$ & None & $91 \%(80 \%, 102 \%)$ & $\oplus \oplus \circ \bigcirc$ low \\
\hline Health care staff with SARS who did not take hand disinfection measure & 3 & 81 & Serious $^{1}$ & Not serious & Not serious & Serious $^{3}$ & None & $57 \%(0 \%, 100 \%)$ & $\oplus \oplus \bigcirc \bigcirc$ low \\
\hline Health care staff with SARS who did not wear masks & 3 & 81 & Serious ${ }^{1}$ & Not serious & Not serious & Serious ${ }^{4}$ & None & $7 \%(0 \%, 16 \%)$ & $\oplus \oplus \circ \bigcirc$ low \\
\hline
\end{tabular}

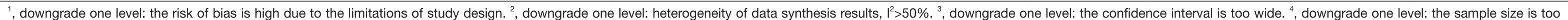
small. $\mathrm{Cl}$, confidence interval; CS, cross-sectional study. 